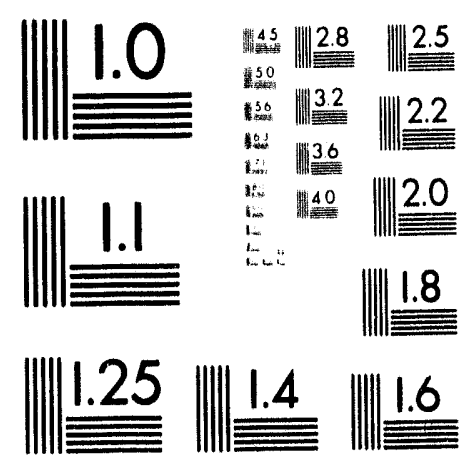



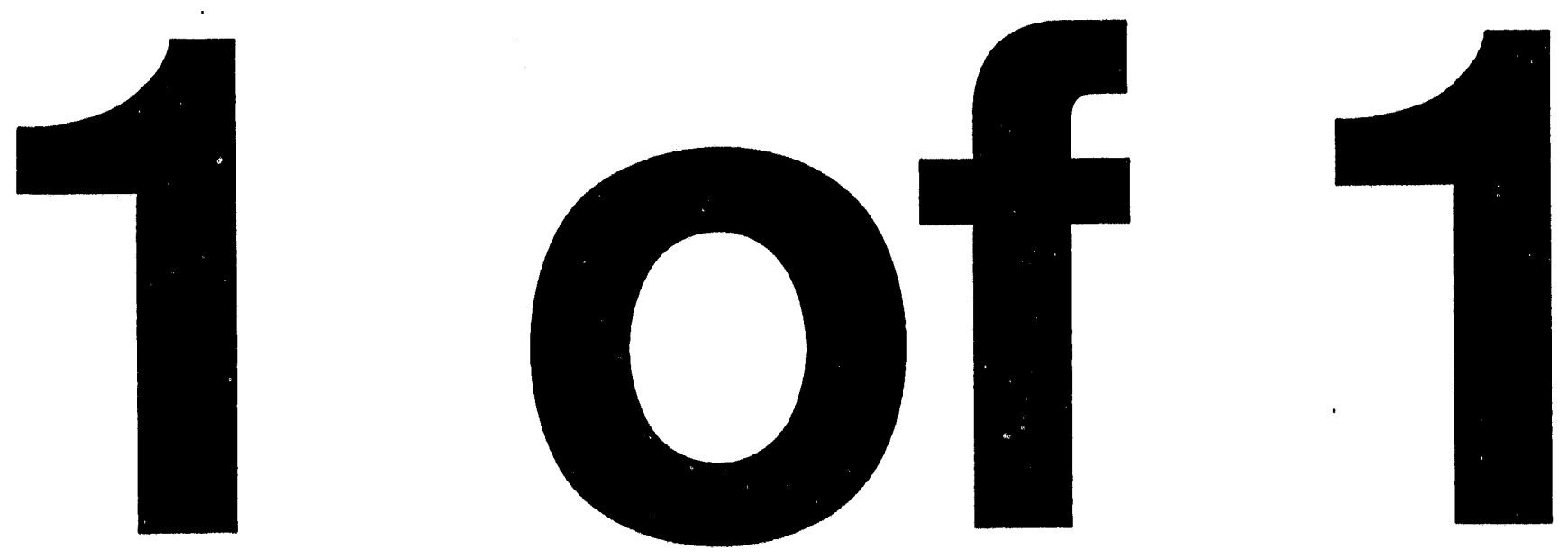
New Mexico Supercomputing Challenge

1993 Evaluation Report

\section{Mary Trainor}

Pat Eker

David Kratzer

Marilyn Foster

Margaret Anderson 


\section{CONTENTS}

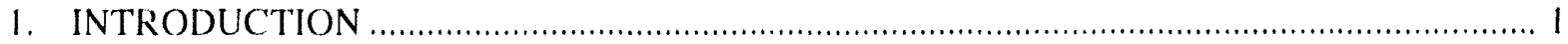

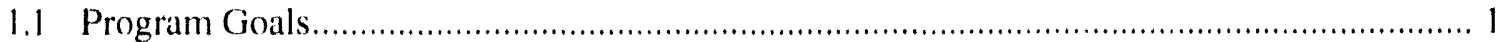

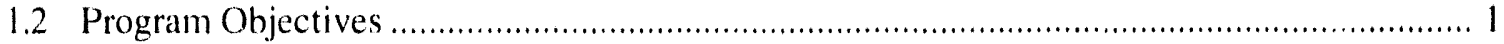

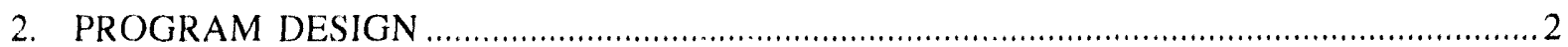

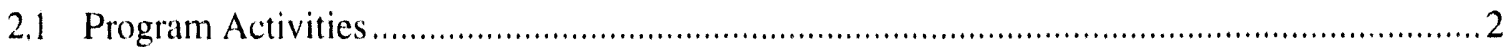

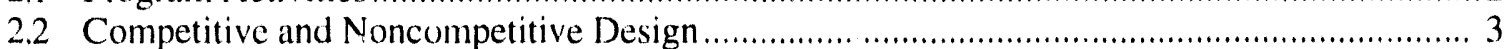

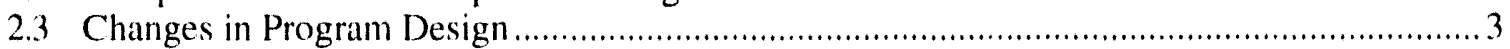

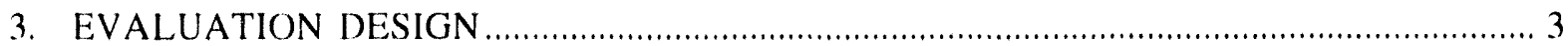

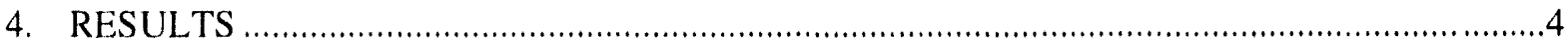

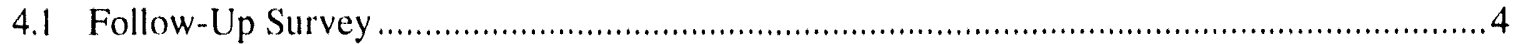

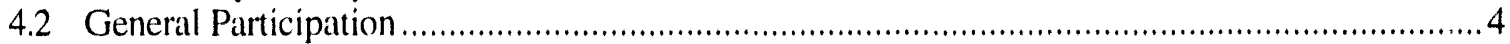

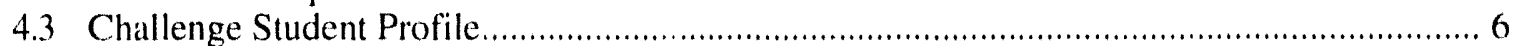

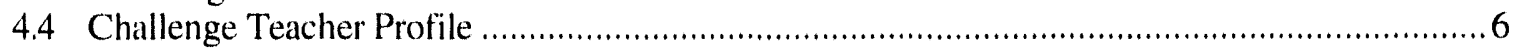

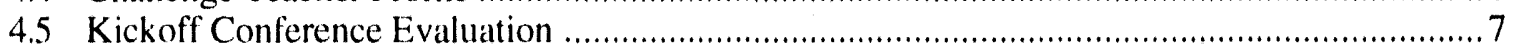

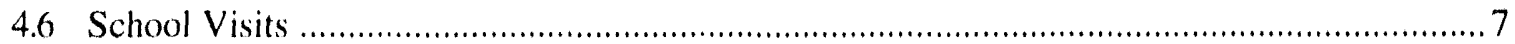

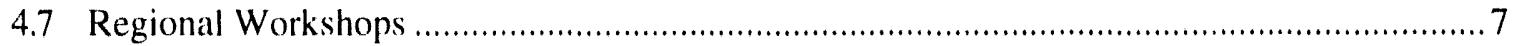

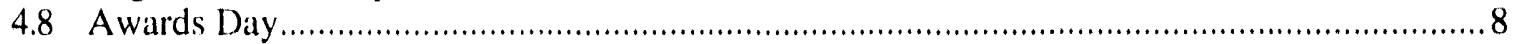

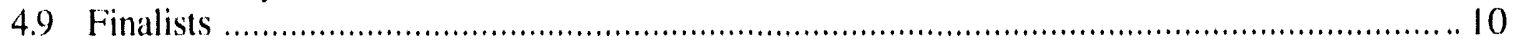

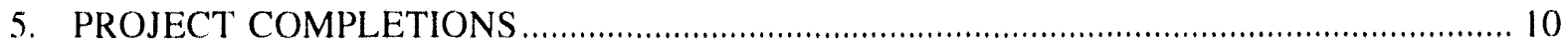

6. DISCUSSION

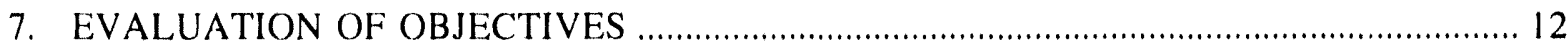

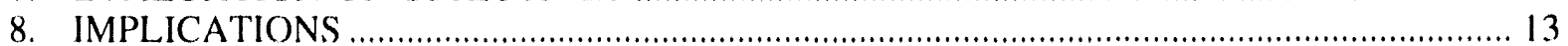

APPENDIX: Anecdotes and Quotes from Challenge 1993 Student and Teacher Participants ........... 14

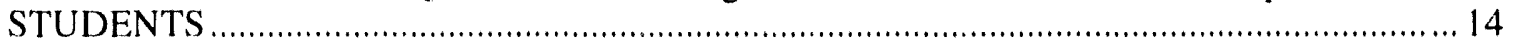

TEACHERS …

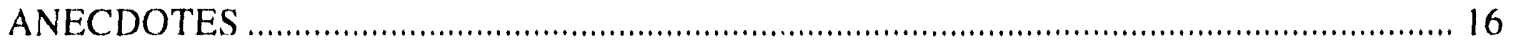




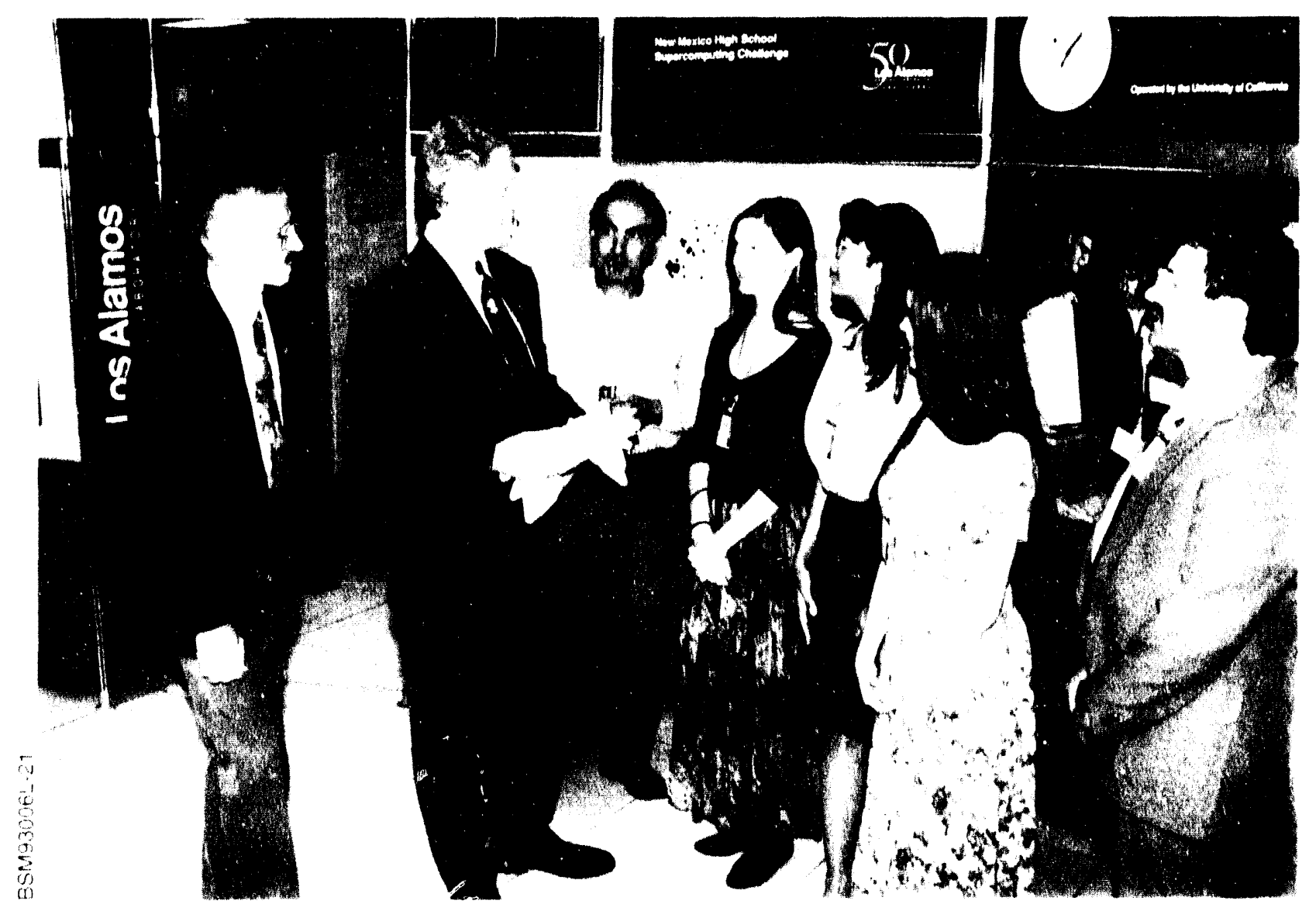

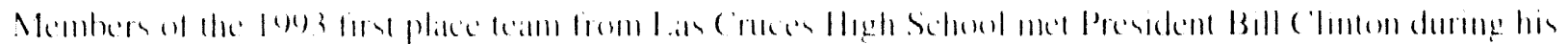

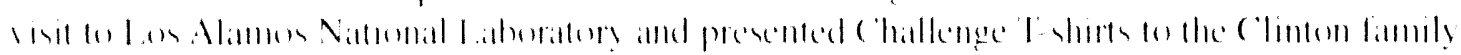




\title{
New Mexico Supercomputing Challenge 1993 Evaluation Report
}

\author{
by \\ Mary Trainor, Pat Eker, David Kratzer, Marilyn Foster, and Margaret Anderson
}

\begin{abstract}
This report provides the evaluation of the third year (1993) of the New Mexico High School Supercomputing Challenge. It includes data to determine whether we met the program objectives, measures participation. and compares progress from the first to the third years. This year's report is a more complete assessment than last year's, providing both formative and summative evaluation data. Data indicates that the 1993 Challenge significantly changed many students' career plans and attitudes toward science, provided professional development for teachers, and caused some changes in computer offerings in several participating schools.
\end{abstract}

\section{INTRODUCTION}

This evaluation report is a second assessment of the New Mexico High School Supercomputing Challenge, which completed its third year in April 1993. New Mexico Technet; Los Alamos National Laboratory (LANL); Phillips Laboratory (PL); Sandia National Laboratories (SNL); the University of New Mexico; New Mexico School of Mining and Technology; New Mexico State University; Digital Equipment Corporation; Cray Research, Incorporated; and others collaborated to sponsor the Challenge.

The Challenge is an academic-year-long program for teams of one to five high school students and their sponsoring teachers. The program is open to all New Mexico high school students.

Challenge observers have asked, "Why should high school students use supercomputers?" This report answers that question in qualitative and quantitative assessments. This year's evaluation is the most comprehensive to be performed thus far. Many new insights regarding technology in the schools and in the lives of students and teachers were obtained.

\subsection{Program Goals}

The main goals of the Challenge are to foster creativity in devising computational solutions to scientific problems and to make a positive difference in students' lives, motivating them to prepare for the workforce of the fitture. The Challenge State Committee developed objectives to meet these goals.

\subsection{Program Objectives}

We evaluated the 1993 Challenge to determine whether the program met the Challenge State Committee's objectives discussed below.

\section{Objectives That Address Students and Teachers}

Provide access to high-performance computers so that teams can conduct complex scientific inquiry, experimentation, and simulation;

Increase high school students' interest in science-related disciplines and promote careers in science and engineering by instilling enthusiasm in students, their families, and their communities:

\section{Develop students' conficience to perform} complex problem solving through their participation in an academically challenging competition; 
Institute electronic networking among all schools to reduce the isolation of students and teachers in remote locations;

\section{Provide an educational experience that is} otherwise unavailable to students and teachers in their regular curriculum; and

Evaluate the effects of a high-performance computer competition on students, teachers, and curriculums.

\section{Objectives That Address the Program}

Design a science and math program that can be replicated in other parts of the United States.

\section{PROGRAM DESIGN}

\subsection{Program Activities}

The Challenge provides events and services to support students, teachers, and coaches throughout the year. The program spans October to April and includes the following activities.

CALL FOR PARTICIPATION: Each high school math/science teacher and administrator receives information about the Challenge and a registration packet early in the school year.

TEAM FORMATION: Students form a team, either as part of a class or as an extracurricular activity. Each team must have a teacher as its sponsor.

KICKOFF CONFERENCE: The Challenge experience begins with a two-day, multitrack conference in October at Glorieta Conference Center. The Conference presents multiple opportunities for students to learn about the Challenge process, computer networks, supercomputers, software development methods, and programming. Two hands-on computer laboratory sessions give students and teachers an opportunity to work in both a structured and unstructured setting.

COACHING: We recruit volunteer scientists and engineers from the national laboratories, industry, and academia to advise teams on both the science and the computing aspects of their projects. Former Challenge participants who are now enrolled in college also coach.

SCHOOL VISITS: A Challenge staff member visits each team at school during November or December to answer questions and ensure that all necessary hardware and network connections are in place.

CONSULTING: LANL, New Mexico Technet, SNL, and PL provide on-line and phone consulting.

NETWORK SUPPORT: New Mexico Technet supplies either a local or 800 number for students and teachers to use for accessing an electronic mail network and reaching the supercomputers at participating laboratories.

REGIONAL. WORKSHOPS: Student teams and teachers attend one of five one-day regional work shops in January or February to address project/technical questions. As part of their instruction, teams also compete to answer basic computing questions.

INTERIM REPORTS: Students who plan to enter the Challenge competition submit a written interim report in January. Judges then review the reports.

JUDGING: A panel of 9 - 12 judge-scientists from throughout the state studies the final report, selects finalists, reviews projects, listens to finalist team presentations, and selects the winners. Students are provided with the following rating system and criteria by the judges.

Scientific Content 30 points Effectiveness of Approach 30 points

Creativity 20 points

Originality 10 points

Clarity

Possible Total

AWARDS DAY: Challenge sponsors supply numerous major and minor awards. In April, the Challenge year concludes with two days of presentations about current scientific and industrial applications and the Awards Ceremony held in Los Alamos. 


\subsection{Competitive and Noncompetitive I)esign}

In the compertitive citlegory, student teams can select and define a scientific problem, write a program to solve the problem, run the program on at supercompuler. and write a summary report to present the project results. Most leams write and edit the code on a microcomputer and then upload the program to debug, generatte graphics, and obtain output on the supercomputer.

Fven teams that elect not to enter the competition learn much about computers and computer applications. They learn to design solfware, lo use electronic mail, wo work as a team, and lo work with scientists.

\section{3 (hanges in Program Design}

In thes third year. we made the following changes in the Challenge program.

TARCETTNG THE: 70\%: The educational component targeced both the $70 \%$ of the students who have little or no computing back ground and are in the (hallenge more to learn than to compete, and the $30 \%$ who ate competitive. Specilically, courses for both callegories were offered at the Kickoft cinference.

\section{EMPHASIZING COMPUTATIONAI SOHENCL:}

The edestational curriculum sressed computational science over computer science, which involved keaching more aboul soltwate engineering and problem solving than programming.

(iNIN(; MORE AWARLS: Every participant should be rewarded. Therefore, eilch person received a minor atward to recognize that he or she had learmed much and demonstratled that learning in his or her performance. At the Challenge A wards Daly, winning teams received trophies, scholarships. and computer equipment. Additionally, poster contest wimners and outstinding Regional Workshop participants won alwards also. Challenge sponsors provided the atwards, and New Mexice fechnel gave at 1-shirt and memento to every pirticipinte

PROIIDINC; BLTTLR COACIIING; We provided andlitional coaching support through a new electronic mail service that allowed a scientist in a particular fiede to answer specific youestions on-line.
ENSURING MORI: PERSONAL ATTENTION:

We supported teams and teachers by providing more individual attention. This is especially critical during the early months of the Challenge, when basic learning occurs and when hardware and connectivity problems arise.

Challenge stalf members also visited each team during the year to note special needs and resolve problems as resources permitted.

Scientists from laboratories, universities, and industries volunteered to coach the teams, with the laboratories and New Mexico Technet providing consulting.

\section{EVALUATION DESIGN}

Our evaluation was designed to determine the benefits of the Challenge and the extent to which the Challenge program achieved its objectives. The evaluation design targeted

Direct affective domain measures to determine participant perceptions of the Challenge impact.

\section{Indirect cognitive domain measures to determine the learning cultivated by the Challenge experience,}

Formative evaluation data to use in planning (hallenge improvements, and

Summative evaluation data to determine the impact of the (hallenge experience on students, leachers, and schools.

We used varied sources and tools for gathering data. Most summative data came from 225 followup surveys mailed to 1991 Challenge participants in order to research the Challenge's long-term impact on any ciareer plans and/or scientific perceptions.

Other measurement tools are listed below according to activities that provided the data.

\section{Kickolf Comferemes}

- Student and teacher background questiomnaires

- Student and teacher formative evaluation questions about the conference

C'minuter Usage'

- Monthly monitoring of LANL's computing resourcer (computer usage at NMSU and SNL. are not reported here. With New Mexico Techner providing connectivity, L.ANI. 
provided the bulk of the supercomputer resources in 1993.)

\section{School Visits}

- Checklist for Challenge staff to complete

Regional Workshop

- Registration form

- Student questionnaire about current progress and problem areas

Awards Day

- Student postevent questionnaire

- Student and teacher critiques

\section{RESULTS}

\subsection{Follow-Up Survey}

The 1991 Challenge participants were sent surveys by mail before the 1992 holiday season to reach college students during their vacations. Fiftieth Anniversary L.ANL huttons and brochures about the history of computing were included with the surveys an incentives to complete the short survey.

Out of the 225 follow-up surveys, we received 59 replies, which is an excellent rate of return $(26 \%)$ for a long-term, follow-up survey. Figure I summarizes the results. Most of the respondents were college freshmen or sophomores $(85 \%)$, but $15 \%$ were still in high school. Most of the college sludents were majoring in either engineering (44\%) or one of the sciences $(41 \%)$. All $(100 \%)$ respondents stated that the recommend the Challenge for all high school students.

\subsection{General Participation}

The 1993 Challenge evaluation results show a positive impact on students, teachers, and schools.

4.2.1 Comparison with 1992. Challenge participation increased in 1993, but the rate of increase is less than in 1992 (Fig. 2 and Table 1). Primarily juniors $(31 \%)$ and seniors $(38 \%)$ participated, and both freshmen and sophomores made up the remainder. Also, seventy-eight students $(18 \%)$ chose to participate for a second or third time. Interviews revealed that returning students either spearheaded new teams or participated in the same team but went further in solving the previous year's problem.

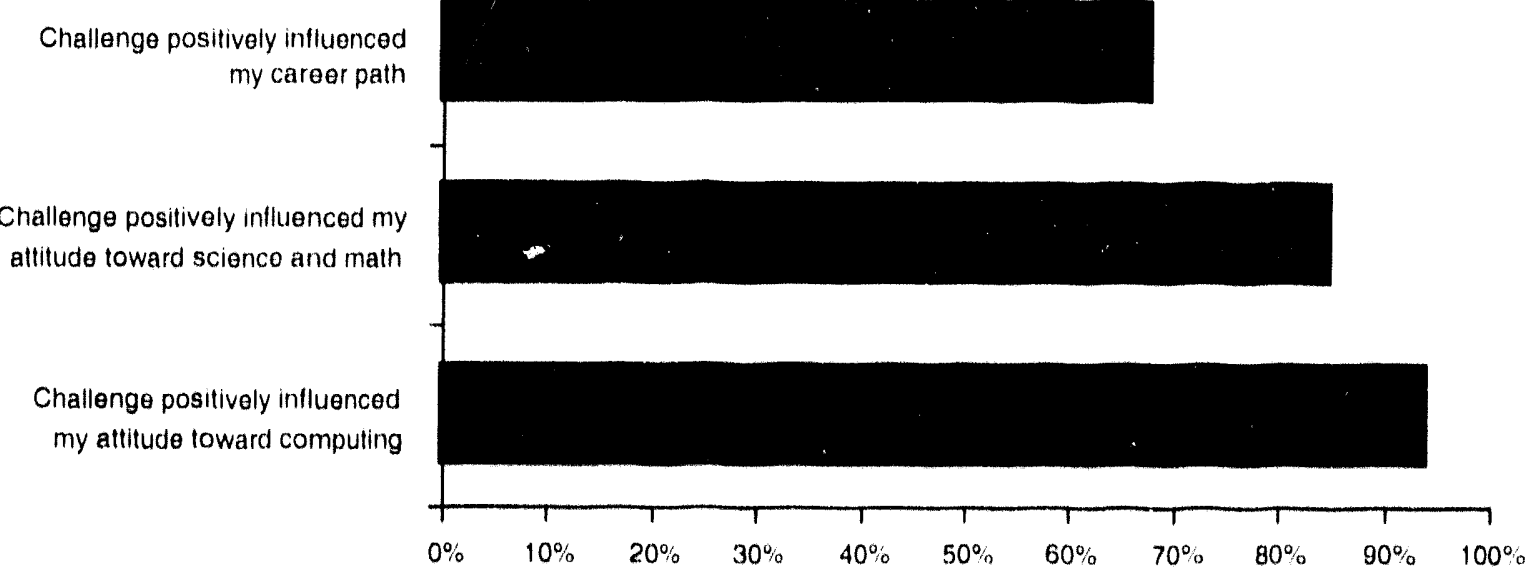

Fig. 1. The follow-up survey shows that the Challenge positively influenced student attitudes. 


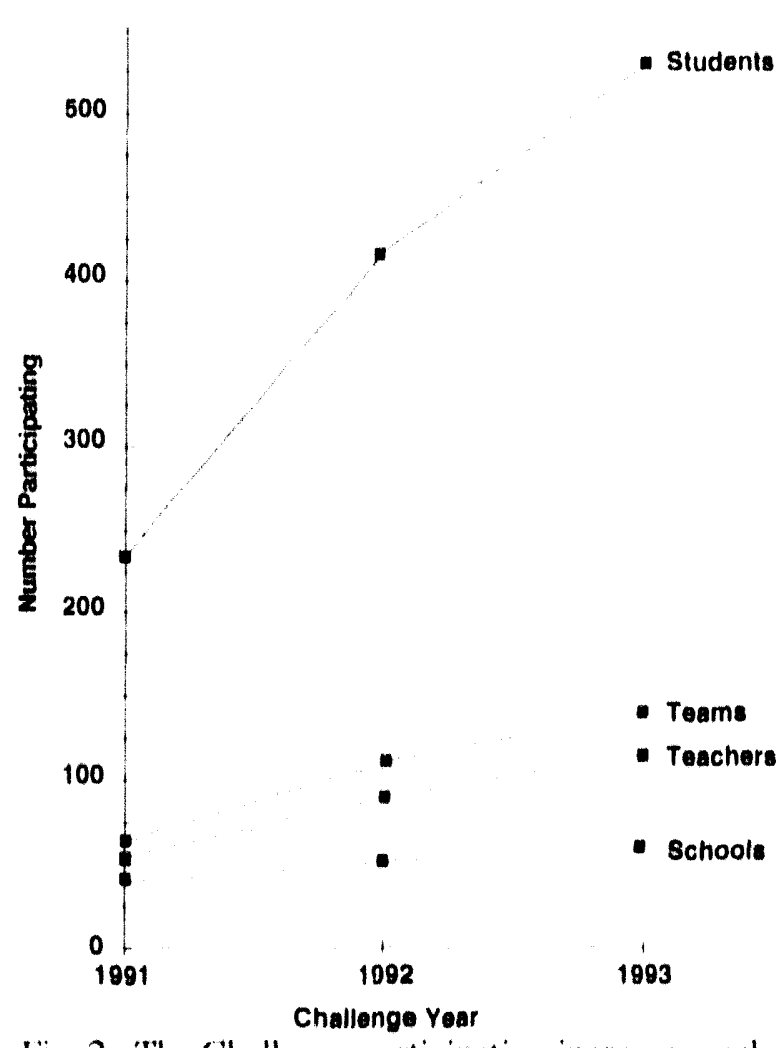

Fig. 2. The Challenge participation increases each year.

Table I. Challenge Participation.

\begin{tabular}{lccc}
\hline & 1991 & 1992 & 1993 \\
Students & 23.5 & 419 & 532 \\
Teams & 0.5 & 112 & 141 \\
Schools & 40 & 51 & 61 \\
Teachers & 5.5 & 91 & 116 \\
\hline
\end{tabular}

\subsubsection{Femule and Ethnic Minority}

Participation. In 1993, female participation totaled $34 \%$, and participation by ethnic minorities was $66 \%$ (Table 2), This body of datti, collected from registration forms that were filly completed, provides a breakdown of student participants both by gender and by ethnicity. The Challenge ethnicity data correspond to the demographies of the state. Ethnic minorities comprise 59\% of New Mexico's population and $56 \%$ of the Challenge participants (Fig. 3).
Tiable 2. 199.3 Student Participation Sorted by lathnicity and (iender

\begin{tabular}{lrr|rr}
\hline & \multicolumn{2}{c|}{ Cender } & \multicolumn{2}{c}{ Total } \\
\cline { 2 - 5 } Ethnicity & Femule & Male & Frequency & $\%$ \\
Anglo & 42 & 101 & 14.3 & 44 \\
Africin Am. & 2 & 2 & 4 & 1 \\
Hispanic & 54 & 86 & 140 & 4.3 \\
Native Am. & 7 & 1.5 & 22 & 7 \\
()riental & 3 & 6 & 9 & 3 \\
()ther & 1 & 6 & 7 & 2 \\
& $10 \%$ & 216 & 325 & $1(0)$ \\
& $(34 \%)$ & $(66 \%)$ & & \\
\hline
\end{tabular}

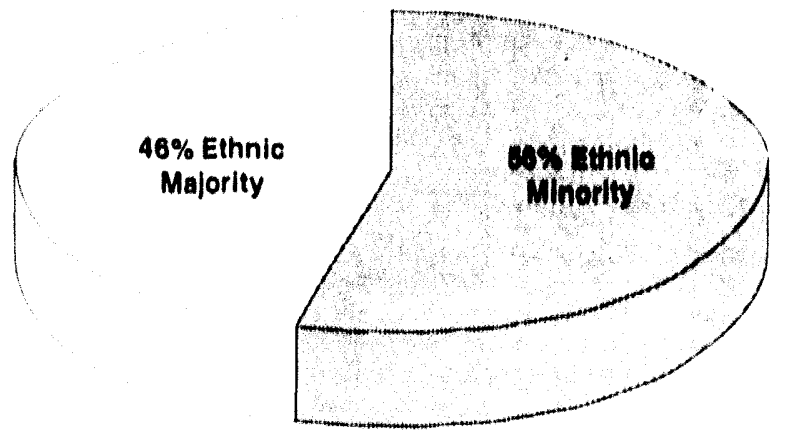

Fig. 3. In the 1993 Challenge, ethnic minorities exceeded ethnic majorities.

4.2.3 Computer Usage. Computer usage statistics for 199.3 show that usage increased disproportionately to the increase in the number of student participants (Fig. 4). In 1991, students used the Cray CPU for 8.5 hours, in 1992 for 300 hours, and in 1993 for 740 hours. Second-year students, peer teaching, and teachers' added experience created this expanded usage.

In addition to comparing past usage data, this year we collected more detailed statisties to antalyze monthly and individual usage patterns. Datta in Table 3 reveal that most students logged onto the supercompulers in ()etober (primarily at the Kickoff Workshop) and decreased logons in the following months. The variety of projects, stages of research, and students' interests account for the average decline. In addition, students wrote programs on microcomputers and used supercomputers only to execute the final programs. Thus, the execution stages occurred at different 


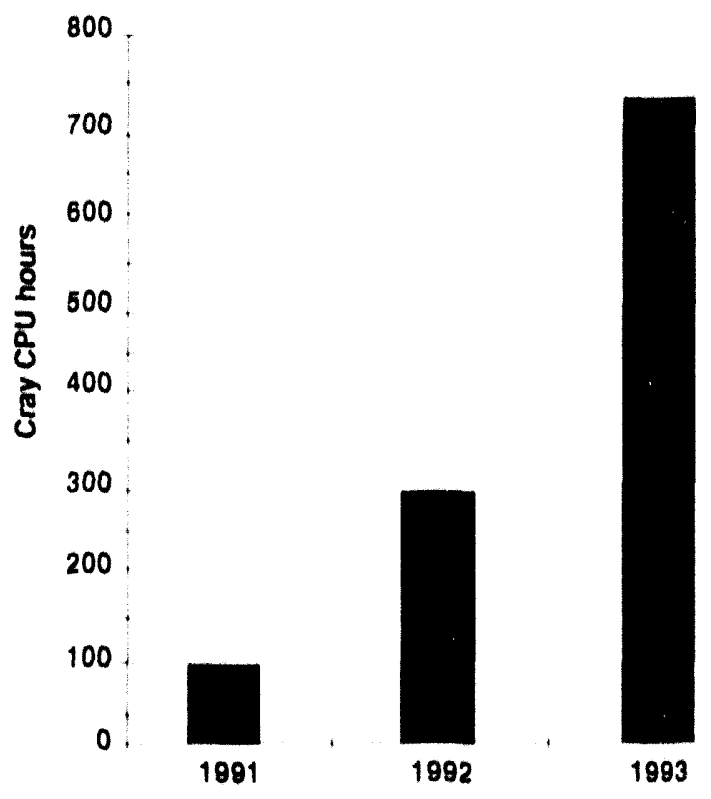

Fig. 4. Cray CPU usage increased from 1901 (1) 1993.

times. Also, most teams did not plan to enter the competition but wanted to begin a project to learn about problem solving with computers.

\subsection{Challenge Student Profile}

At the Kickoff conference we gave students ant Fvaluation Booklet in which we asked questions about their backgrounds and interests. The sample size obtained in this way was very large (4.39). The answers furnished not only a baseline with which to compare attitude changes during the Challenge year but also a profile of a typical challenge student. The profile changed some of our assumptions and also gave us information about computer availability and experience.

The Kickoff evaluation data show that most 1093 participants

- had prior experience on more than one computer system:

- had some background in BASIC programming:

- did not have a computer al home:

- were new to the Challenge this year:

- signed up for the Challenge to increase their knowledge (not for the awards);

- expected to learn more aboul programming. using supercomputers, and solving problems with computers through the Challenge:
- were already interested in careers in either the sciences or enginecring; and

- planned to go to a 4-year college.

The Kickoff student profile data is especially interesting. The profile indicates an improvement in the hardware skill level and in the amount of computer technology in New Mexico school curriculums. Note, also, that the (hallenge population is large and representative of the statte and its wide range of school sizes. Interviews pointed out, however, that a wide range existed in the amount of stpport, the type of hardware, and the connectivity available at the schools. Having no phone lines available to dedicate to the Challenge created a significant harrier for many schooks.

\subsection{Challenge T'eacher Profile}

Al the Kicholf conference, we collected for the lirst limes back ground informallion about the (hallenge keacher population and their schools. The response rale wis very high, with 89 of the 116 leachers responding. The 1993 " allenge keacher profile is as follows:

- Fifty-two pereent were new to the (hallenge However, minlly worked in schools thall participated previously. A total of 75\% of all leachers tallght in former Challenge schools.

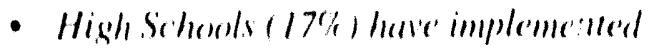
improverments in compunter ronurses and hardware as a result of the ('hallemger.

- All but one Challenge teacher was computer literate, and 69\% had compulers all home.

- Other teachers, students, or the principals ellouraged about half of the participating leatehers to join the Challenge. The remainder participated after reading about the ( hallenge.

()lle leacher said this about the value of the (hallenge experience:

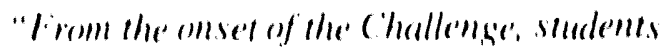
and leachers are assisted in setting their programs, becoming familiar with reguipment, and establishing ties with others utrilising the las Alomess supercomputers. Fricendships are developed and the competition begins. fion reachers, the opportumity to deverlops 


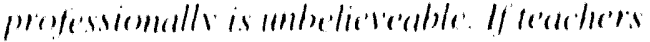

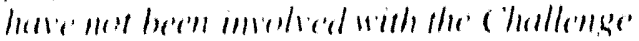
int. ST:Rl Now!"

\subsection{Kickoff Conference Evaluation}

Participants in llac kickulf comlerence completed a formative evallations. The response ratte (89\% of 116 teachers alnd $8.3 \%$ of 5.32 students) provided a representative sample population.

Studedts $(89) \%$ ) and leachers $(100 \%)$ ratted the Kickoff conference an Villuable. Both leatehers (9)\%) alld stedents ( $84 \%$ ) ralled the computer hands-ons sessions an the most viluable part of the conference, and students suggested addding more of lhose sessions as an improvement for mext year (We doubled the number of sessions this year.)

In adddition for receiving hands-onl compuller axperience. this yeatr's participantes hatd a chotice of

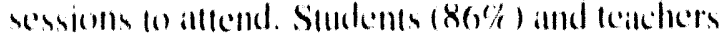
(97\%) rilled highly the opportunity to select their own sessions.

Most stldedents also sitid lley fell more confident and excited aboun the ("i. .llenge alfer the Kickolf (72\%) and more knowledgetible about the rules and procedures of the (hallenge (77\%), Because they worked in schools and homes sometimes remolely locialed, stedents needed to know how to ged assistance when problems allose. Mons students (77\%) sitid that alfer the kickofl they knew where

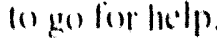

Another key to dhe ( 'hatlenge' success was llat

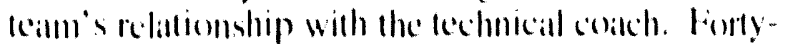
four pereent of the stokents were able to lialk with

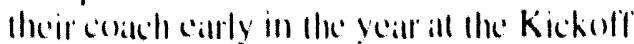
conference.

The Kickofle conference evaluation also anked about students' and leitchers' experience with the ('hallenge. Must students (76\%) and many leatehers $1.52 \%$ ) were new to the (hallenge this year. (A lew of the repeatting leatehers did not altend the Kickoll (innference.)

We used the (ilorietas conference cenner for the Kickolle for the first lime this year. Most students (72\%) and leikehers (94\%) rated the fictility an gend. Teidehers (79\%) and stldents (47\%) sitid the food was also idedeyuatle.

\subsection{Sichool Visils}

In November and December, onc or lwo representittiven of the ('hallenge Statle Commilter visiled eateh leaml. The visit required selling up ippointments, coordinating visits within one

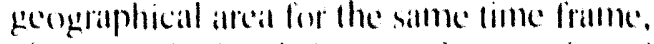
whtaining leedback from students and leachers, and then responding to that feedhatek. School visits oceurred for the first time this vear and replaced the first un of regiomal wothshops held in the past awo yearls

The individual sehool visits were a greall stecess. Karly in the Challenge year, the visits exposed locial problems thall could be obstacles (1) keall abilitien to meed their objectives. These obstacles were agressively pursued after diagnosis during on-site visits. (Ohsticless included

- the lick of an ansigned cuach ,

- all inability to contiact the colich.

- inn inability focomect to Techned (ustally the lick of a phone line),

- all inoperable personal computer.

- the lack of the correct compiler on the persomal compulter.

- the lack of andeyuate computing information lo incomplish the project.

- He lack of holowledge about Challenge resultices, and

- a projece that was for ambitious for the time ilvililable.

Although costly for the Challenge staff that performed them. the visits proved to be vital to genting leams underwaly carlier than in past yeatss. Becialse of limiled resources, however, the statf could not remove every obstacle. Some of those obstacles will continue to exist becianse the Challenge resources cannot provide solutions (e.g.e. phone lines).

\subsection{Regional Workshops}

We held regional workshops in five different locittions in the state during January and February. Teachers and coatches allended with their student keams. The se workshops were one-day sessions locited at universities or community colleges. We designed the workshops to help leams progress, regardless of their accomplishments up to that point. We tailored content and format to stldent needs att that point and conducted competitive sessions with leams being anked to allswer commonly ansed computing questions. Teams received points for correct answers. We identified the leam receiving the most points ats a "Regional Hot Shot" and gave prizes. Furthermore, a breakout fime allowed each leam to meed with an expert to discuss a topic of the leamls choice. 
The workshop registration and evaluation forms revealed much about progress and needs (Table 3). Note that after 3 months in the Challenge. most teams were still defining the problem and doing research or heginning to program.

Table 3. Team Status in January-February.

$\%$ of teams

Teamwork, brainstorming

19)

Define problem, research

2.5

Define problem, programming

31

Program refined and debugging

15

Other

On the workshop registration form, students also indicated the technical areas in which they wanted help (Table 4). Giaphics and programming languages created the highest levels of interest. Students had progressed fitr enough in their projects to realize the importance of these skills in achieving their objectives. However, work shops do not include instruction in programming languages. Instead, we provided tutoring and consulting and loaned instructional videotapes to schools as needed.

Table 4. Students' Requests for Help. (Students could choose all that applied.)

\begin{tabular}{ll}
\hline Programming languages & $68 \%$ \\
Graphics & 63 \\
Writing Challenge report & 37 \\
File transfers & 31 \\
UNIX/UNICOS & 29 \\
Preparing poster & 26 \\
Judging & 23 \\
\hline
\end{tabular}

\subsection{Awards Day}

The Awards Day activities included two days of judging, tours, and an awards ceremony. The judging took place on the first day. Teams arrived early in Los Alamos to begin 30-minute presentations to the judges. Also the media interviewed and filmed each finalist team. All

teams, including the nonfinalists, enjoyed tours and attended the awards ceremony.

The tours this year gave students not only a view of the Cray supercomputers and the Thinking Machines ( $\mathrm{CM}-2$ and $\mathrm{CM}-5)$ but also a snapshot of computational science at work at LANL. Scientists demonstrated research applications ranging from materials science to biology and environmental science.

Al Awards Day, participants were asked to complete a questionatire so that we could collect iffective postevent information. Figure 5 depicts stludents' learning expectations at the Kickoff Conference and their realized learning by the culmination at Awards Day. Note that students learned more than they expected about supercomputers and problem solving but less than they expected aboul programming. This was an

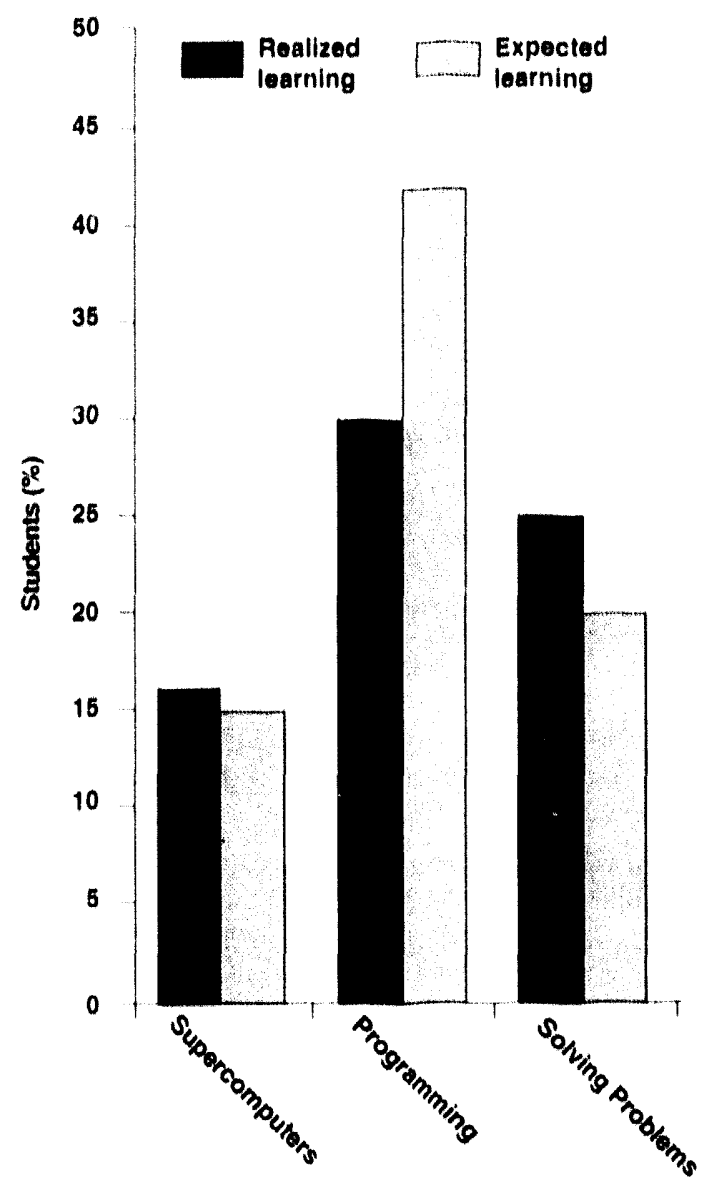

Fig. 5. Students rated their expected learning and their realized learning. 
expected and favorable outcome because many students initially equate programming with computational science. Therefore, in the educational components of the Challenge, we stressed problemsolving methods and presented programming as a tool.

Figure 6 presents further data showing that almost all participants rated the Challenge to be a valuable experience and one that improved both their attitude and knowledge about science/engineering and math.

The Awards Day evaluation provided additional data that indicated positive feedback about the
Challenge's effect on the choice of a career and/or college major. We asked students about their career expectations at both the Kickoff Workshop and the Awards Day and found that the Supercomputing Challenge influenced $67 \%$ of the students in their career-related choices (Fig. 7). Many students selected more specific areas of science, while others moved from nonscience to science (Table 5). Only $30 \%$ did not change career expectations between October and April. We had incomplete data on $24 \%$. The remaining $46 \%$ changed lateraly from one area of science to another.

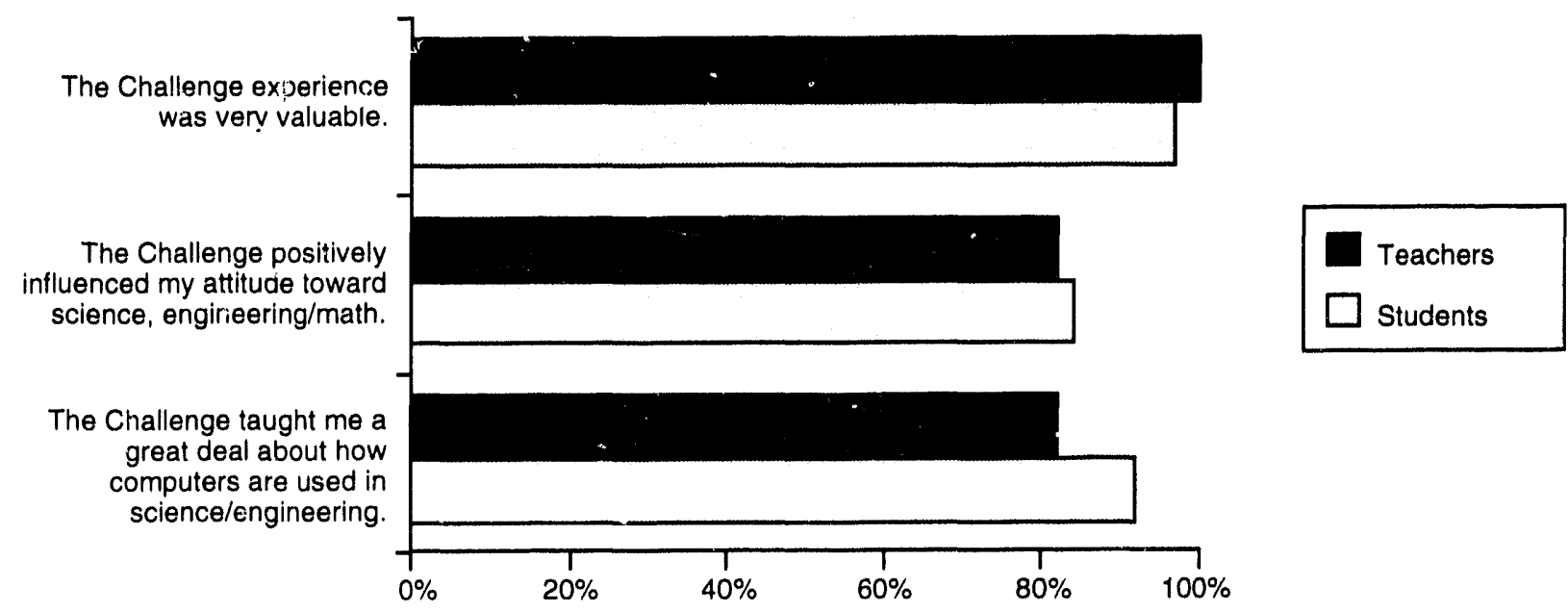

Fig. 6. Students and teachers rate the values of the Challenge.

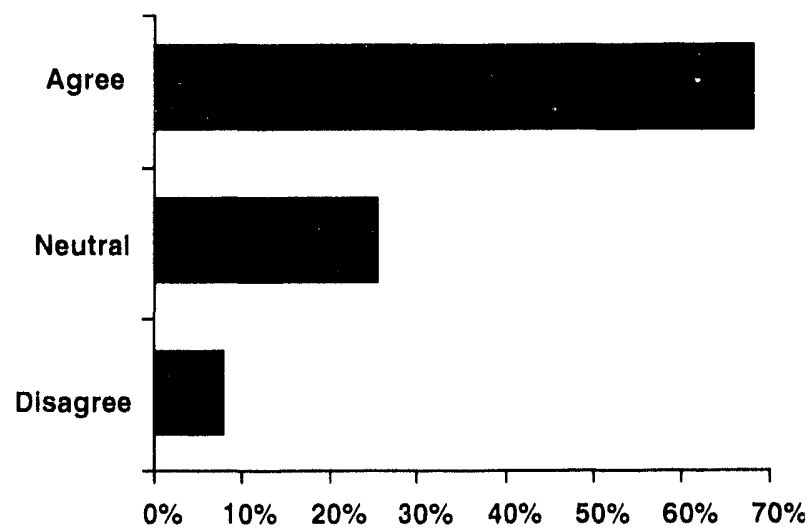

Fig. 7. Students agreed the Challenge would influence career choice/major in college. 
Table 5. Examples of Student Changes in Career Plans from the Beginning to the End of the 1993 Challenge Year.

\begin{tabular}{|c|c|}
\hline From & To \\
\hline $\begin{array}{l}\text { English } \\
\text { Health } \\
\text { Engineering } \\
\text { Business/Accounting } \\
\text { Undecided } \\
\end{array}$ & Computer Science \\
\hline $\begin{array}{l}\text { Computer Science } \\
\text { Art } \\
\text { Health }\end{array}$ & Engineering \\
\hline Computer Science & $\begin{array}{l}\text { Health } \\
\text { Biology/Chemistry } \\
\text { Engineering } \\
\text { Earth Sciences } \\
\end{array}$ \\
\hline Social Sciences & Physical Sciences \\
\hline Health & Earth Sciences \\
\hline Art & Psychology \\
\hline
\end{tabular}

We also collected significant qualitative information about the diversity of the tours. For the first time, many students saw the careers available in science, saw scientists at work, and observed examples of computational science projects underway.

\subsection{Finalists}

Twelve teams were chosen on the basis of their interim reports. In April these teams made presentations to judges who selected and ranked the six top finalists.

The large number of minority and female top finalists is noteworthy. On the six top finalist teams, $77 \%$ of the team members were female and $83 \%$ were minorities, a quite different composition than that of the overall Challenge population. However, judges did not record participant gender and ethnicity; they asked each team the same questions and determined top finalist teams through an objective multivoting process.

Therefore, it is clear that the Challenge competition provides an attractive opportunity for ethnic minority and female students to excel. Finalist students disclosed in interviews that many thrived in the creative, self-paced, coached team learning environment, where they had much responsiblity and tailored help.

\section{PROJECT COMPLETIONS}

Seventy-three teams chose to compete and submitted interim reports. The competition was completed by $30 \%$ of all Challenge teams that submitted interim reports.

What happened to the rest of the teams that did not enter the competition? Interviews revealed that this year many teams began a project they plan to submit for judging next year. These teams saw their first year of participation as a time to learn the basics of programming, networking, and computing on the supercomputers and anticipate competing the second year. Other teams saw the Challenge as a valuable learning experience and were not interested in competing. Six Challenge teams withdrew because of

- lack of support by a coach and/or teacher,

- lack of time (committments in sports and other activities were too demanding), and/or

- personal reasons (unexpected events arose in the students' lives, causing them to feel they could no longer participate).

We compiled this list of reasons from verbal or electronic exchanges with the teams.

Table 7 lists the project titles of the 12 finalists. Note the great range not only in subject areas but also in degree of sophistication. 
Table 7. Project Titles of 1993 Challenge Finalists

- Computer-Simulated Ecosystem

- Supercomputer Simulation of Brittle Fracture

- A Study of Kinematics Involving a Motion Analysis of Classical Balletic Movements

- Baseball Simulator 1.0

- Creating a Geographical Information System (GIS) and Using It to Locate Lightning Strikes in New Mexico

- A Critique of Methods for Performing Numerical Simulations of the Long-Term Motion of the Solar System

- Balloon Tracking

- Measuring the Ozone Using a High-Altitude Balloon

- Two-Dimensional Placement of Objects

- Predicting the Depletion of the Ozone Layer

- A Six-Hour Simulation of an Unenvironmentally Controlled House

- Brute Force Reality: Simulating Mass and Gravity in Three Dimensions

\section{DISCUSSION}

This section offers an interpretation of the collected data and integrates direct observations. Exposing students to the prevailing method for solving real-world problems through the Challenge experience changed their lives and ambitions. Participants saw for the first time that they could indeed make a difference in this world and could accomplish more than they thought. As a result of the Challenge, most students now seem to be able to make choices that better prepare them for careers.

The data we collected this year revealed a great deal about the Challenge student and teacher populations. The profiles of both populations revealed an interest in computers and a zeal to know more.
In this third year, we implemented changes to the Challenge program and analyzed the results. A discussion of programmatic changes and our success follows.

TARGETING THE 70\%: We modified the Kick off Conference to include special sessions for the $70 \%$ who had little or no computing background as well as for the $30 \%$ who were experienced. The data indicates our overwhelming success in this modification of the education component.

EMPHASIZING COMPUTATIONAL SCIENCE: We emphasized computational science both in the Kickoff Conference sessions and in the Awards Day presentations. In the Kickoff, we offered a two-hour session on this subject, and in the Awards Day activities, we gave tours focused on solving scientific problems with computing (as opposed to a focus on the computers and software).

Participants rated these sessions very highly.

GIVING MORE AWARDS: At the awards ceremony we gave both major and minor awards. We added sponsors' awards, along with the "Regional Hot Shot" awards, and LANL provided the first Award for Environmental Modeling. This diversification was very well received.

PROVIDING BETTER COACHING: A special electronic mail service that allowed students to consult with subject area experts was initiated midyear and has yet to be fully developed. Some subject area experts were not yet identified. There was a shortage of coaches this year, as the time c. mmmittment for volunteers is large and the number of teams has increased. Therefore, we failed to fully implement this change and are planning a more realistic approach for 1994 .

During interviews, we collected anecdotal information that suggests the success of a team is partially related to the amount of attention the technical coaches and/or teachers provide. Obtaining technical coaches is difficult, so some teams had no coach. While some coaches spent several hours almost every week with their teams, other coaches were available only by phone or electronic mail when problems arose. Additionally, the teacher population is bimodally split. Teachers are either nontechnical sponsors, filling the role of administrator and encourager to the team, or they are technical sponsors actively involved in the problem-solving aspects of the team's project. 
ENSURING MORE PERSONAL ATTENTION:

We successfully addressed this plan in one area of the Challenge. We replaced the first set of regional workshops with individual team visits at the schools by one or more members of the Challenge staff.

\section{EVALUATION OF OBJECTIVES}

The goals of the Challenge are to foster students' creativity in devising computational solutions to scientific problems and to make a positive difference in students' lives, motivating them to prepare for the workforce of the future. The appendix data, the list of project titles, the responses to the Awards Day questionnaire, and the computer usage statistics indicate that the Challenge met these goals.

OBJECTIVE 1: To provide access to high pe" rormance computers so that teams can conduct complex scientific inquiry, experimentation, and simulation.

DISCUSSION: The Challenge met Objective I in 1993. All teams used high-performance computers throughout the Challenge as well as in the Kickoff Conference laboratory sessions.

OBJECTIVE 2: To increase interest in sciencerelated disciplines among high school students and promote careers in science and engineering by instilling enthusiasm among students, their families, and their communities.

DISCUSSION: We directly measured and met this objective in 1993. We administered pre-event and postevent questionnaires to discover changes in career interests. Data indicate that students felt the Challenge would indeed have a large impact on their career choices, and many students did change their career interests more toward science by the end of the Challenge. The Follow-up Survey of 1991 participants furnishes the most conclusive data. Two years after participating in the Challenge, the majority of the respondents said the experience did indeed impact their choices of career/college majors.
OBJECTIVE 3: To develop student confidence to perform complex problem solving through their participation in an academically challenging competition.

DISCUSSION: We qualitatively measured and met Objective 3 for many Challenge students as well as for teachers. Informal interviews and observations provided the data. Many students said that as a result of their experience in the Challenge, they knew they could achieve success in a scientific field, thus revealing an increase in confidence.

OBJECTIVE 4: To institute electronic networking among all schools to reduce participants' isolation in rural/remote locations.

DISCUSSION: We unquestionably met Objective 4. Students communicated electronically not only with their coaches but also with other students they met at Challenge workshops and, in at least one case, with scientists studying the research problem internationally. There is still much technical work to be done, however, in terms of providing universal connectivity in the schools.

OBJECTIVE 5: To provide for students and teachers an educational experience that is not available to them in their regular curriculum.

DISCUSSION: We reached Objective 5 in 1993. Teachers clearly pointed out that the Challenge provided an educational experience unavailable to students through their regular curriculums. The Challenge also encouraged schools to provide better support for students by providing computing software, hardware, and courses. Student-led pressure on the schools' administrations gave the impetus for these advances. In fact, one former Challenge student who entered college this year expressed disappointment in the university's computing resources. He expected the university to provide resources similar to the Challenge.

OBJECTIVE 6: To research and evaluate the effects of an academic competition that uses high performance computers. 
DISCUSSION: We met Objective 6.

Reporting the effects of the Challenge is this document's purpose. Our evaluation builds upon the last year's data to provide basic assessment information. This years' evaluation was much more extensive and revealing than last year's. Part of the evaluation wass collecting supercomputer usage statistics; the usage statistics from the supercomputers at Los Alamos reveal that usage on the machines shot t1p in 1993. Student supercomputer literacy is increasing each year as the Challenge program matures.

OBJECTIVE: 7: To design a science and math program that can be replicated in other parts of the United Stittes.

DISCUSSION: We realized (objective 7 in 1993. We received inquiries from 1.3 other states including Minnesota. Arizoni, Montana, and Filorida. By interasting and sharing materials, we allowed others to learn about the Challenge program. We worked oo form a nationwide consortium to support high school supercomputing programs.

\section{IMPIICATIONS}

Our data supports the claim that the (Challenge met all sevell objectives for 1993 and reached the goals to foster creativity in devising computational solutions to scientific problems and to make a positive difference in students' lives, motivating them to prepare for the workforce of the finture. We also stlceessfully execuled four of the five strategies for change proposed in the 19022 (hallenge evaluation. (Our findings clearly indicate that the Challenge program stecessfully motivated students and leachers of learn lo use high-performance computers lo solve real-world problems. In addition, as the Appendix shows, the Challenge changed several students' career plans. The Challenge is a program that is better prepatring both teachers and students for the futture.

Our evaluattion also points out improvements we should make in the challenge program for 1994, and the Challenge State Committee is planning those changes. These improvements include more teacher training. Our ability to implement improvements depends on the funding that Challenge sponsors can provide. Resources are limited, yet the needs are growing. Therefore, the
1904 Challenge will focus on planning more cost effective components and on using our limited resources to the greatest benefil of students. teachers, and schools. 


\section{APPENDIX \\ Anecdotes and Quotes from Challenge 1993 Student and Teacher Participants}

\section{STUDENTS}

"I joined the Challenge because I was intrigued at the chance to use some supercomputers. I didn't have any idea at all what supercomputers were, and neither did anyone else in the group. Our first year on the Challenge was spent figuring out E-mail and asking questions like, "What is a modem?" After the awards ceremony that year we decided to try a serious project for the next year. We spent the summer attempting to learn the $C$ language and hand picked our own technical coach, who helpea develop our original idea into something feasible. After that we worked hard. More than anything, I truly valued the experience the whole Challenge offered. I didn't realize until late in this year's Challenge how truly privileged I was to be so intimate with the most powerful computers in the world. I also had a bunch of fun. Everyone was so nice, friendly, helpful, and excited. It was well worth the time and frustration." (female finalist)

"The Challenge sparked an interest in me in a more scientifically oriented career, whereas I hadn't previously considered it seriously. I learned a lot ubout computers; before I knew very little more than how to turn a computer on and use WordPerfect. Being with each other as a group forced is to learn how to work together. Initially I thought this was just a competition for computer nerds and the kickoff would be like a "Geeks R Us" convention, but I met a lot of great people who have a lot going for them. Everyone at the Challenge has been warm and friendly and supportive." (junior finalist)

"My mom told me that I could never be an engineer and someone else told me that it would be too difficult. Then we won and my mom couldn't say that engineers never earned anything and it was an unworthy job for anyone. I can now say that it may be hard, but I stand a chance. While it was confusing at first, I got used to it and really learned a lot." (female first place winner, minority')

"I feel this is an excellent opportunity to learn more about computers. I have seen from others how being part of the Challenge can help you in furthering your education. I am interested in solving problems in science using computers and I hope to continue and further my education in a field involving both." (sophommore participant)

"The Challenge is a program that provides excellent hands-on experience for any high school student with an interest in computers. I want to earn as much experience with computers as I can. I am aware of the time and dedication required, and am giving all." (female minority participarm)

"I am interested in the Challenge because 1 am interested in continuing the great status and recognition that my community gained as a result of winning the Challenge last year. I am also deeply interested in computers and all the great wonders they are cupable of and I enjoy designing and researching projects." (sophmore, minority finulist)

"I like the Challenge because I want to compete against other schools. This makes me want to work harder to prove fo other schools and people that our school isn't as bad as they say it is. I also am getting experience working with other people as a team and with computers. My goal in life is to be a computer scientist." (jumior, mimority' fimalist) 
Two individual scholarship winners told us

They were both one of several children and had little hope or no hope of getling to go to college. Now they would get (1) go! (O) of the winners was working while finishing her senior year to help with the family experises.)

\section{TEACHERS}

"The students involved have learned a great deal about the supercomputer. The teachers are becoming more involved in computer technology as at result of their exposure in sponsors. The benefits to the school are significant now and will continue to be in the future. We are anxious to expand on this technology in making our school a positive role model in dealing with computers."

"My team made me very proud in how well they interacted with their conch. Al lirst they found him intimidating, hut gradually they gained more confidence and assurance and developed a wonderful intellectual and emotional relationship with their coach. In some ways it was a relationship of ecuatity which I believe is an important lesson for students to learn."

"This was owar first year, so it was a totally 'different world" of computing for our students. Awe insperime!."

"This experience is invaluable to me and to my students."

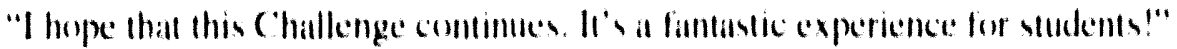

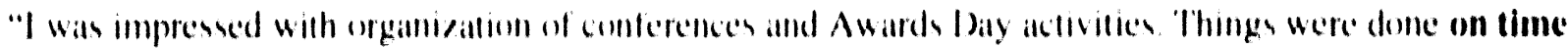
and well-planned. KUI)( IS!"

"I allm at big heliever in the ( hallenge Keep up the gonod work!"

"Keep the program going, it? great!"

\section{One 'Teucher's Story}

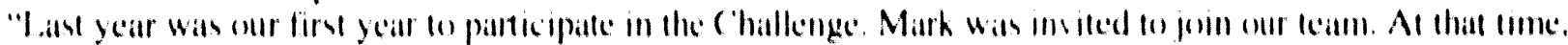
he had an acceptable knowledge of compulers and some limited experience with BASIC . He Was

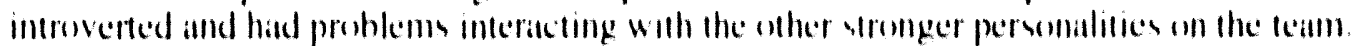

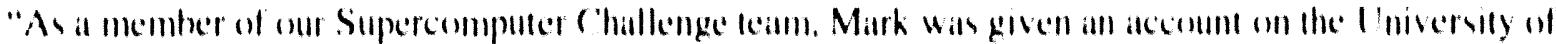

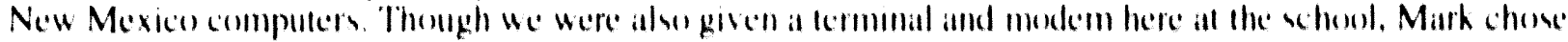

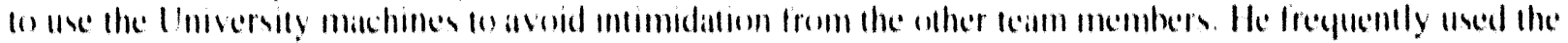

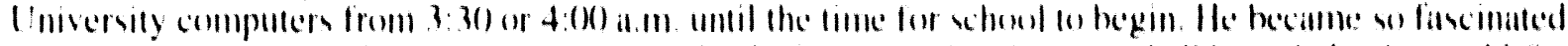
wilh the wonderful world of supercomputing that he heyan we abouth anly and all knowledge he conded find ithent supercomputers.

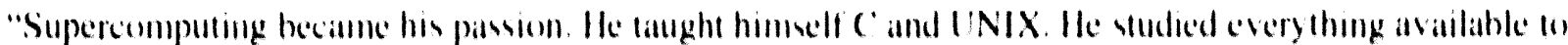
him and worked hard at learming all he conde about superommputers.

"()ur leam didn't 'gu any where' that firs year in the ('hallenge, hut Mark grew in so many ways as a resull

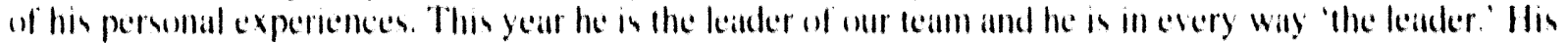


whole personality has changed as a result. He even ran for a school office this year and won!!! The Challenge, in Mark's case, has taken a very shy. quet, uninvolved individual and furned him into a confident, self-assured, involved member of our stludent body. He even has a paying joh for writing programs for a local computer firm.

"Sandia Prep owes a lot to the Supercomputing Challenge and we are very thankful for the incredible opportunities afforded us by this program.

"As the sponsor, the inspiration I have received from watching Mark's personal, edacilional, social, and business growth will sustain me to continue the Supercomputing Challenge at our school, if the opportunity continues. Personally, there are no words to express my appreciation for this unique experience created by the Supercomputing Challenge."

\section{ANECDOTES}

One of the finalist teams selected a research problem related to lightning. They shose that lopic beciuse a friend of theirs from their school was struck by lightning and killed last summer while playing baseball. They wanted to better understand how lightning worked. and help anoid these kinds of accidents in the future.

Another team chose a project on the parking configuration (painted lines) in their high whool foothall field lot. They had observed a real problem with cars leaving after the games, if an emergency oscurred. as the parking was disorderly and inefficient. They presented their project to the Sihool Board at the conclusion of the Challenge A wards Day, and won support from the School Board for the parking lot redesign.

\section{Se'verul teachers told us about}

The school board or principal getting them beller sompuler of communicittoms sequipment for their classroom because they salw what the students were learning in the (hallenge.

The shy student who "eame out of his/her shell" is a member of a challenge keam. 

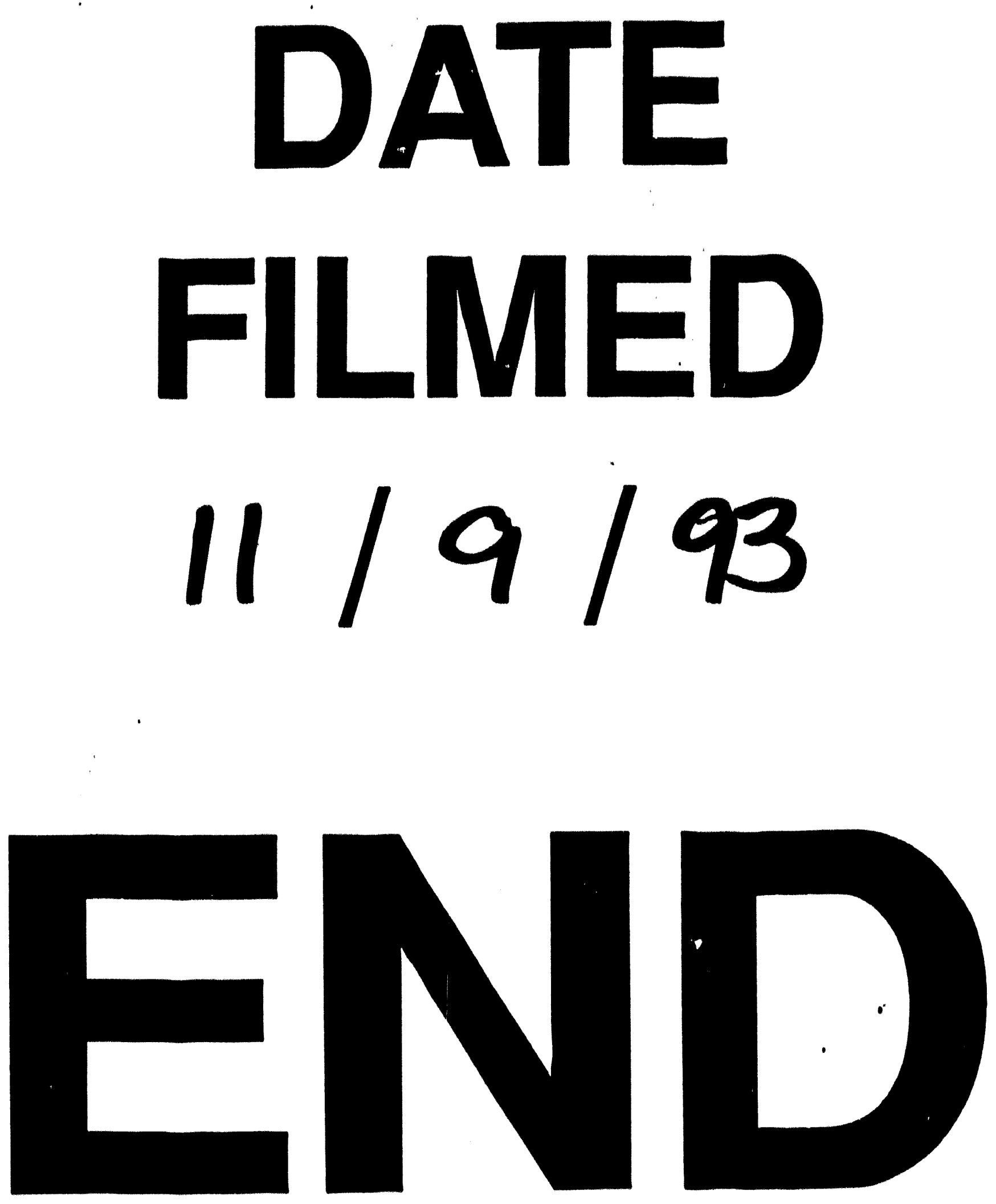
